\title{
Temperature- Dependent Mechanical Properties of PVDF/graphite Composites
}

\author{
G. M. Elkomy ${ }^{a}$ M. H. Abd-El Salam ${ }^{* b}$, H. Osman ${ }^{c}$, M. R. Nagy ${ }^{b}$ \\ and F. El-Sayed ${ }^{b}$ \\ ${ }^{a}$ National Research Center, Dokki, Cairo, Egypt \\ ${ }^{b}$ Physics Department, Faculty of Education, Ain Shams University, \\ Cairo, Egypt \\ ${ }^{c}$ Physics Department, Faculty of Science, Cairo University, Giza, Egypt.
}

Poly (vinylidene fluoride) (PVDF)/graphite composites were prepared by solution mixing technique then subjected to hot compression molding. Tensile mechanical properties of prepared composites were studied at different temperatures between 30 and $90{ }^{\circ} \mathrm{C}$. The results indicated that, the elastic modulus, tensile strength, and ultimate elongation achieved a significant improvement with addition of graphite showing maxima around $3.9 \mathrm{vol} \%$ graphite, followed by a decrease with further increases of the graphite content. This behaviour suggested the formation of a compact structure, and above a content of $3.9 \mathrm{vol} \%$ graphite, this compact structure became more loose. These results were confirmed by both SEM and DSC measurements. DSC measurement indicated that graphite content has significant influence on the degree of crystallinity for PVDF composites. Also, study of the melting behaviour suggested the presence of only $\alpha$-crystalline phase in neat PVDF and $P V D F / G$ composites. The observed values of the elastic modulus of the composites are in close agreement with those calculated by Halpin-Tsai's model, taking into account the variation of the aspect ratio $\left(\alpha_{g}\right)$ of the graphite structure with the volume fraction of the graphite in the matrix. The elastic modulus, tensile strength and yield stress were found to decrease with increasing the working temperature, while the ultimate elongation exhibit opposite trend.

\section{Introduction}

Polymer/graphite composites have been employed in structural, aerospace and sporting goods.Recently; increased attention has been devoted to develop graphite/polymer composites as high conductive polymers [1]. In addition to high electrical conductivities, these so-called conductive polymer 
composites (CPCs) often possess other desirable properties, such as improvement of mechanical performance, thermal stability, corrosion resistance, low cost and ease of processing. Given this combination of properties, polymer/ graphite composites present an attractive alternative to metal conductors in certain applications, provided that sufficient electrical conductivity can be achieved. Poly vinylidene fluoride (PVDF) is a semi crystalline and thermoplastic polymer, which can be easily processed, and has excellent mechanical properties, high chemical resistance and good thermal stability as well as high pyro- and piezoelectric coefficients [2]. PVDF has been widely studied because of its relatively large piezoelectric and pyroelectric response and the abundance of its polymorphic forms that have been exploited in the development of electronic devices. PVDF has five crystalline phases with different conformations are designated like all trans (TTT) planar zigzag for $\beta$-phase, TGTG' for $\alpha$ and $\delta$ phases and $\mathrm{T}_{3} \mathrm{GT}_{3} \mathrm{G}^{\prime}$ for $\gamma$ and $\varepsilon$ phases. [3] These different crystalline forms affect directly thermal, mechanical and electrical properties of the structure.

Graphite is a polycrystalline form of carbon comprised of layer planes containing hexagonal arrays of carbon atoms. These layer planes, referred to as graphene layers, are ordered so as to be substantially parallel to one another. The bonding forces holding the graphene layers together are weak Van der Waals forces and hence the layers can be readily separated. Graphite is one of the most important inorganic fillers which possess good electrical conductivity and high modulus. [4] In addition, graphite is naturally abundant low cost material. Although there has been much work in the field of PVDF-based composites, little work on the mechanical properties of PVDF/graphite composites has been carried out.

Siviour et al. [5] studied the stress-strain behaviours of polyvinylidene difluoride (PVDF) over a range of strain rates at room temperature and a range of temperatures at high strain rate. PVDF shows an approximately bilinear dependence of yield stress on strain rate over the rates examined. L. Laiarinandrasana et al [6] studied the mechanical behaviour of Polyvinylidene Fluoride (PVDF). Tests were performed at various temperatures and various strain rates. Experimental data together with fracture surface examinations by SEM allow the dependence of deformation and void growth processes on strain rate and temperature.

The principal objective of this study is to study the effects of graphite content and temperature on the morphology (i.e. void content and crystallinity) of poly(vinylidene fluoride) (PVDF) composites and the concomitant effects of these morphological changes on the mechanical properties. 


\section{Experimental}

\subsection{Materials and sample preparation}

The used poly vinyledine fluoride (PVDF) is white powder, molecular weight of $\mathrm{M}_{\mathrm{w}}$ 534, supplied by Sigma-Aldrich Chemie GmbH Riedstrasse 2 Co.,. The physical properties of the host material are shown in Table 1[5]. Graphite fine powder with particle size $(50 \mu \mathrm{m})$ was provided by Central Drug House (P) LTD, New Delhi. N,N-dimethylformamide (DMF) were used directly without any further treatment.

Table 1: Physical properties of PVDF

\begin{tabular}{|c|c|}
\hline Glass transition temperature & $-30{ }^{\circ} \mathrm{C}$ \\
\hline Melting point & $165^{\circ} \mathrm{C}$ \\
\hline Density & $1.74 \mathrm{~g} / \mathrm{cm} 3$ \\
\hline Tensile modulus & $2400 \mathrm{MPa}$ \\
\hline Tensile strength at yield & $53-57 \mathrm{MPa}$ \\
\hline
\end{tabular}

The PVDF/graphite composites were prepared by mixing the desired amount of graphite particles and PVDF in $100 \mathrm{ml}$ of DMF solution at $80{ }^{\circ} \mathrm{C}$ under stirring for $2 \mathrm{~h}$. The mixture was poured onto the Petri dish and dried at $180{ }^{\circ} \mathrm{C}$ for 25 minutes to remove DMF solvent. The samples with a thickness of $1 \mathrm{~mm}$ were molded by a hot press at about $155^{\circ} \mathrm{C}$ and 20MPa for 5 minutes and then quenched in cold water. The graphite volume fractions of composites were fixed at $0.7,2.3,3.9,5.5,7.9$ and $11.1 \mathrm{vol} \%$.

\subsection{Measurements}

\subsubsection{Scanning electron microscopy (SEM)}

The morphology of tensile fractured surface was observed using scanning electron microscopy (SEM) type, JEOL JEM-850 operating at $35 \mathrm{kV}$. All specimens were coated with a thin gold layer prior to SEM examination. The SEM data were obtained using Leica Qwin 500 Image Analyzer Computer System (England).

\subsubsection{Differential scanning calorimetry (DSC)}

The melting behaviours of the composites $\left(\mathrm{T}_{\mathrm{m}}\right)$ and heat of fusion $(\Delta \mathrm{H}$ ); were estimated by differential scanning calorimeter (Chimadzu DSC-50) from $40{ }^{\circ} \mathrm{C}$ to $200{ }^{\circ} \mathrm{C}$ at a heating rate of $10{ }^{\circ} \mathrm{C} / \mathrm{min}$ under $\mathrm{N}_{2}$. By considering 
the melting enthalpy of $100 \%$ crystalline PVDF $\left(\Delta \mathrm{H}_{\mathrm{o}}\right)$ as $104.6 \mathrm{~J} / \mathrm{g}$ [7], we have estimated the degree of crystallinity $\left(\chi_{c}\right)$ of neat PVDF and PVDF-graphite composites by the equation

$$
\chi_{c}(\%)=\frac{\Delta \mathrm{H}}{\Delta \mathrm{H}_{o}} * 100
$$

\subsubsection{Mechanical testing}

The PVDF/graphite composites were subjected to tensile testing for determination of their mechanical behaviour. Strip shaped samples were cut from the sheets by a fine edge steel die with a constant width of $2 \mathrm{~mm}$. The apparatus used for stress-strain measurements was a tensile test machine (AMETEK, USA). A digital force gauge (Hunter Spring ACCU Force II, $0.01 \mathrm{~N}$ resolution, USA) connected to a microprocessor was used to measure extension force. A homemade motor attachment was used to control the strain rate through a gearbox. The strain rate was preset using a variable DC power supply, and was measured using a micro-switch attached to the apparatus wheel. The accuracy of strain measurement was about $0.1 \mathrm{~mm}$. The elongation rate throughout the experiment was fixed at $8 \mathrm{~mm} / \mathrm{min}$.

\section{Results and Discussion}

\subsection{Scanning electron microscopy (SEM)}

To investigate the effect of stretching on the morphology of PVDF and PVDF/graphite composites, SEM micrographs were obtained as shown from Fig. (1). The results indicated that the pure PVDF; exhibits raised structure, as shown in Figure 1(a). The raised structure might be related to the stacked crystalline lamella in the PVDF sample [8]. The microstructure of neat PVDF affected by filler addition of $0.7 \mathrm{vol} \%$ and $2.3 \mathrm{vol} \%$ graphite as observed from Figure1b,c. where the addition of graphite deforms the nature of such raised structure of lamella. The flakes nature of graphite introduces pores through the fractured surface indicating loose structure [9]. Further addition of graphite to 3.9 and $5.5 \mathrm{vol} \%$, the structure of the fractured surfaces appears to be more compact. This may be due to the aggregation of graphite flakes with the layered structure of PVDF (see Figure1d,e). Increasing the graphite concentration to $7.9 \mathrm{vol} \%$ and $11.1 \mathrm{vol} \%$ graphite retains the loose structure as in the case of $0.7 \mathrm{vol} \%$ and $2.3 \mathrm{vol} \%$ graphite (Fig. 1f,g). 


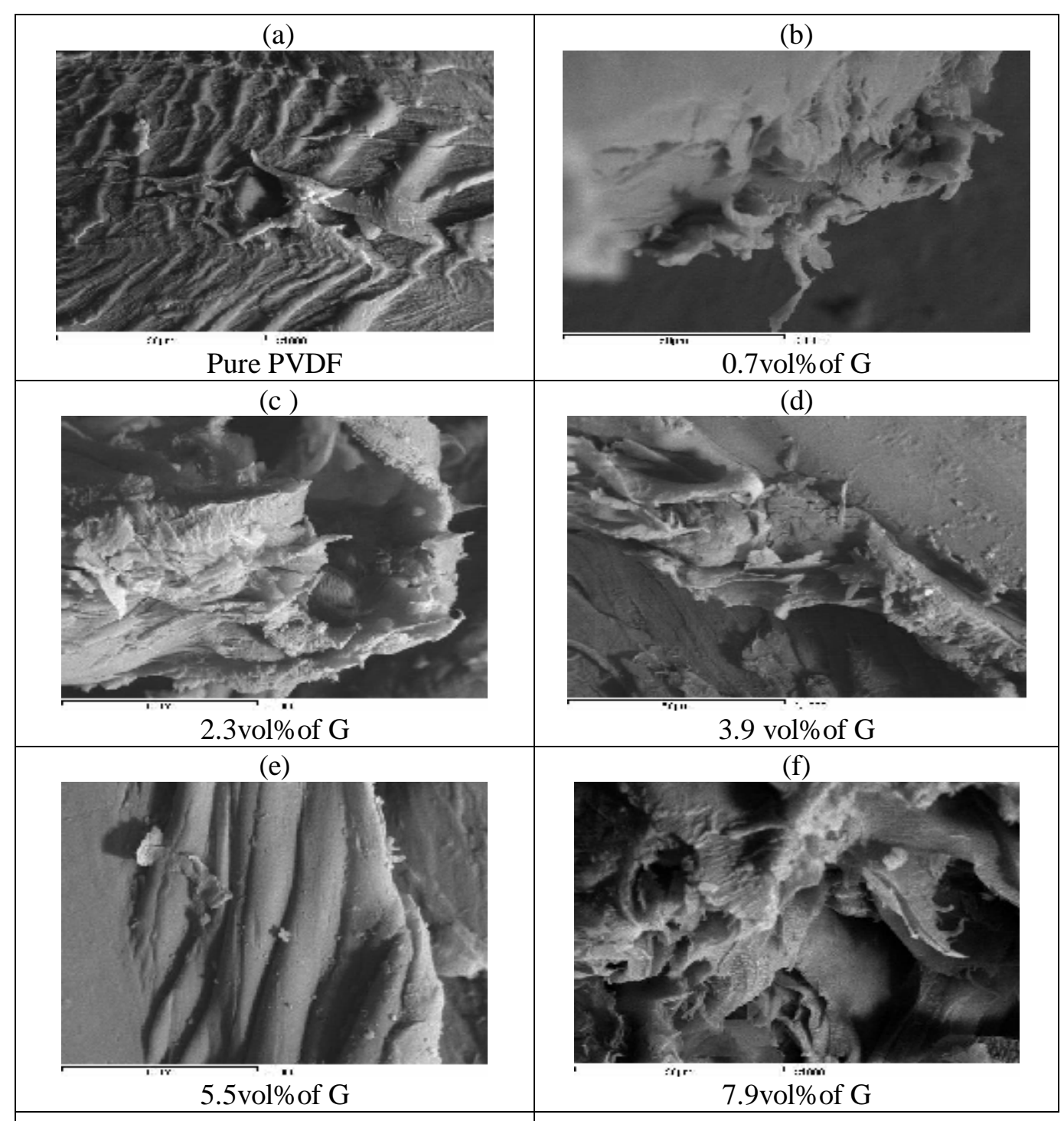

(g)

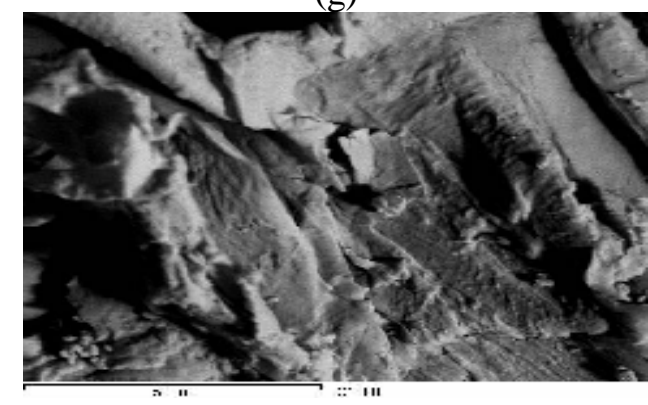

$11.1 \mathrm{vol} \%$ of $\mathrm{G}$

Fig. (1): SEM photographs of pure PVDF and PVDF /graphite 


\subsection{Differential Scanning Calorimetry (DSC)}

Since PVDF is a semicrystalline polymer, its mechanical properties should depend strongly on its degree of crystallinity. Crystallinity in polymers means that the chains are packed together more tightly which increases the density of the polymer and leads to improved mechanical properties [10]. To confirm the influence of incorporating graphite into PVDF on the mechanical enhancement of the composites, DSC is employed to measure the difference of crystallinity between pure PVDF and PVDF/G composites (Fig. 2). The degree of Crystallinity of PVDF was calculated according to Eq. (1), and the results are shown in Table 2. The degree of crystallinity of PVDF decreased from 27.65 to $19.63 \%$ at $0.7 \mathrm{vol} \%$ graphite. This indicates that the graphite addition process leads to partial destruction of the crystalline structure. The increase in graphite content up to 3.9 volt $\%$ increases the degree of crystallinity to $25.31 \%$. Any further increase of graphite content decreases the crystallinity of the composites again. On the other hand, the melting temperature does not vary much with addition of graphite, indicating that no phase transformation takes place between the five phases of PVDF with addition of graphite. The lower melting temperature is due to the formation of $\alpha$-crystalline phase structure [11].

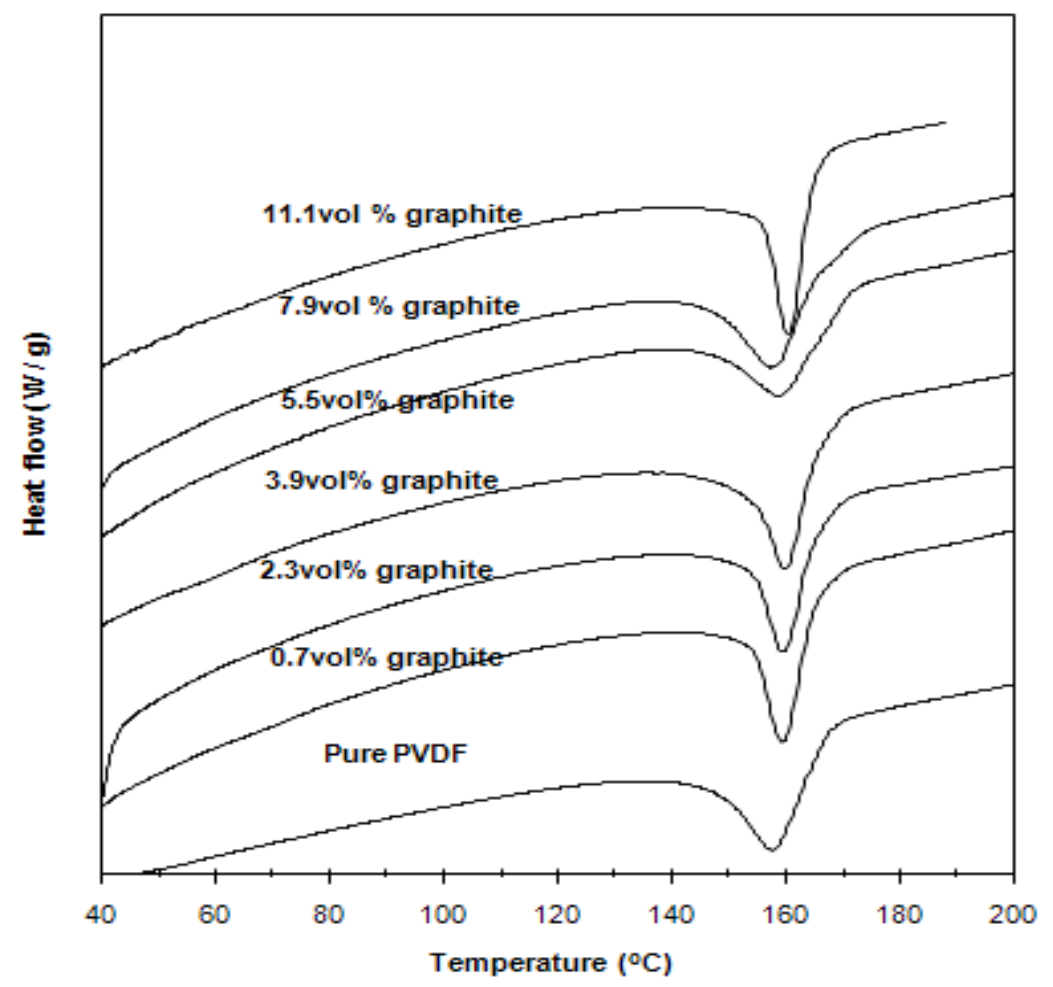

Fig. (2): dynamic DSC thermograms of the PVDF-graphite composites. 
Table 2 : The derived values of $T_{m}, \Delta H$ and $\chi_{c}$ from the DSC thermographs.

\begin{tabular}{|c|c|c|c|}
\hline Content of graphite (vol\%) & $\mathbf{T}_{\mathbf{m}}\left({ }^{\mathbf{0}} \mathbf{C}\right)$ & $\mathbf{\Delta H}(\mathbf{J} / \mathbf{g}) \Delta H$ & $\mathbf{c}(\boldsymbol{\%}) \boldsymbol{\chi}$ \\
\hline Zero & 157.72 & 28.96 & 27.65 \\
\hline 0.7 & 159.62 & 20.56 & 19.63 \\
\hline 2.3 & 159.57 & 24.68 & 23.57 \\
\hline 3.9 & 159.94 & 26.51 & 25.31 \\
\hline 5.5 & 158.86 & 24.94 & 23.82 \\
\hline 7.9 & 157.43 & 20.18 & 19.27 \\
\hline 11.1 & 160.46 & 17.76 & 16.96 \\
\hline
\end{tabular}

\subsection{Strain-stress behaviour at room temperature}

Graphite powder has been applied to enhance the mechanical properties of composites. Fig. (3) illustrates the stress-stain curves of PVDF and $\mathrm{PVDF} /$ graphite composites at room temperature and strain rate of $4.4 \times 10^{-3} \mathrm{sec}^{-1}$. According to tensile properties of PVDF and PVDF/graphite composites, which could be seen in Table 3, the mechanical performance of the PVDF/graphite composites, were significantly increased as compared to those of the pure PVDF matrix. For example, at $3.9 \mathrm{vol} \% \mathrm{G}$, the Elastic modulus increased by $35 \%$ from 722.15 to $978 \mathrm{MPa}$ and the tensile strength increased by $20 \%$ from 25.87 to $30.76 \mathrm{MPa}$. Moreover, the ultimate elongation of the composites was increased as compared to pure PVDF. The increase of elastic modulus may be attributed to the higher crosslink density and good distribution of fillers in PVDF matrices. In other words, the uniformity of fillers distribution has efficiently hindered the chains movement during deformation. This mechanism would increase the stiffness of the composites as well as elastic modulus [12]. These mechanical parameters were found to decrease with further increase in the graphite content above $3.9 \mathrm{vol} \%$. The reduction in tensile strength may occur due to the agglomeration of filler particles or simply the result of physical contact between adjacent agglomerates [13]. The agglomerate is a domain that can act like a foreign body in composites. Since there was a high amount of agglomerates in higher filler loading composites, these agglomerates act as obstacles to chains movement and initiate failure under stress. These results were confirmed by both SEM and DSC as was mentioned before, where the compact structure which was formed around the content of $3.9 \mathrm{vol} \%$ graphite is responsible for the maxima in all the above parameters. 


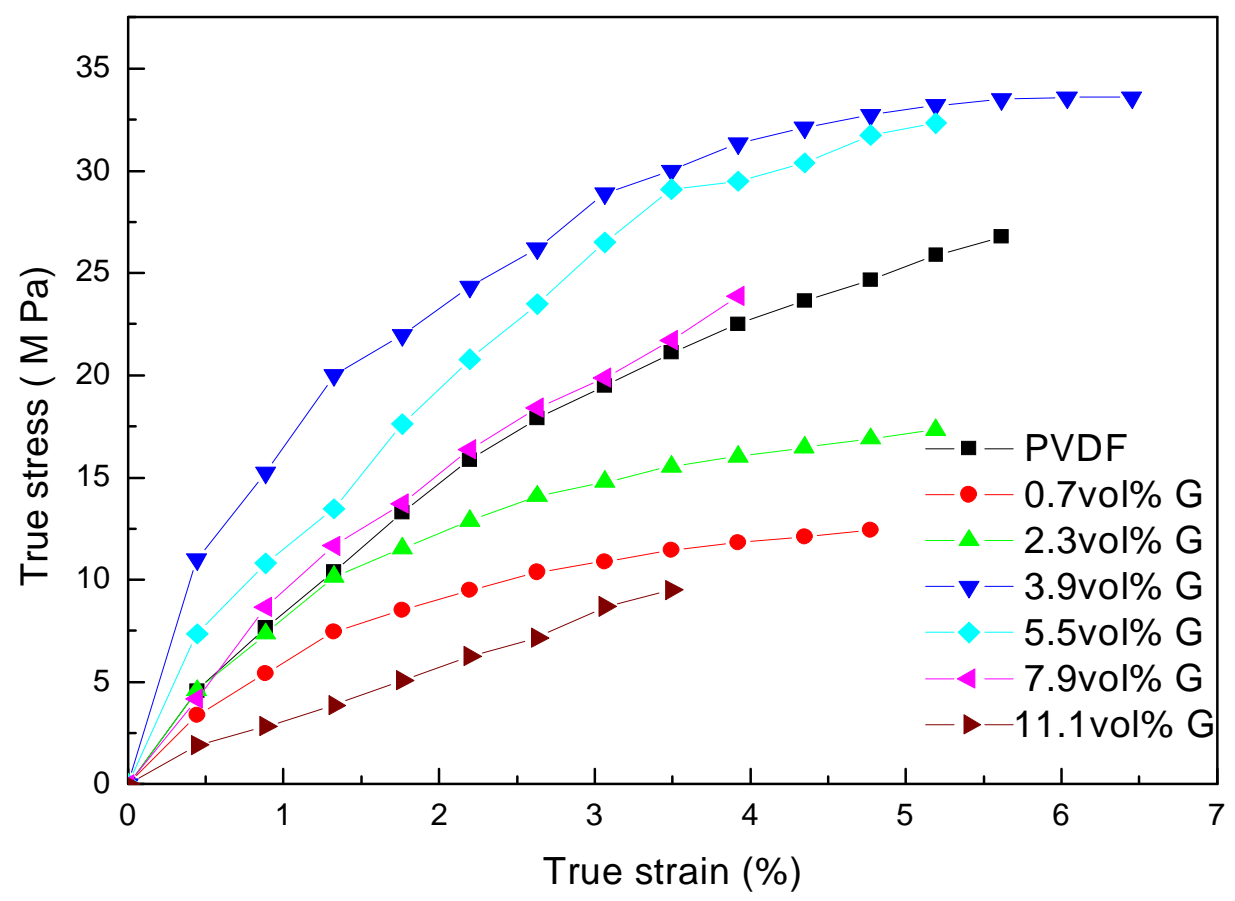

Fig. (3): Stress-strain curves for PVDF and PVDF/ G composites at room temperature

Table 3: Mechanical properties of the PVDF/graphite composites at room temperature

\begin{tabular}{|c|c|c|c|}
\hline $\begin{array}{c}\text { Content of } \\
\text { graphite }(\mathbf{v o l \% )})\end{array}$ & $\begin{array}{c}\text { Elastic } \\
\text { modulus(E) } \\
(\mathbf{M p a})\end{array}$ & $\begin{array}{c}\text { Tensile } \\
\text { strength }\left(\sigma_{\mathbf{R}}\right) \\
(\mathbf{M p a})\end{array}$ & $\begin{array}{c}\text { Ultimate } \\
\text { elongation }\left(\varepsilon_{\mathbf{R}}\right)(\boldsymbol{\%})\end{array}$ \\
\hline Zero & 722.15 & 26.77 & 5.6 \\
\hline 0.7 & 715 & 10.225 & 4.7 \\
\hline 2.3 & 720.54 & 12.68 & 5.19 \\
\hline 3.9 & 978 & 33.59 & 6.45 \\
\hline 5.5 & 966.16 & 32.32 & 5.19 \\
\hline 7.9 & 910.7 & 23.84 & 3.92 \\
\hline 11.1 & 331.44 & 9.48 & 3.49 \\
\hline
\end{tabular}

A trial was made to simulate the modulus of the $\mathrm{PVDF} / \mathrm{G}$ composites using the Halpin-Tsai model which is widely used for predicting the modulus of randomly distributed filler-reinforced composites [14]. Fig. (4) depicts the variation of elastic modulus with the graphite content for the experimental 
results (points) obtained and the solid lines show the theoretical data obtained by applying the Halpin-Tsai model represented by (equations (2-5)).

$$
\begin{gathered}
E_{c}=E_{m}\left[\frac{3}{8} \frac{1+\eta_{i} \xi \varphi_{f}}{1-\eta_{i} \varphi_{f}}+\frac{5}{8} \frac{1+2 \eta_{T} \varphi_{f}}{1-\eta_{T} \varphi_{f}}\right] \\
\eta_{\varepsilon}=\frac{\left(E_{g} / E_{m}\right)-1}{\left(E_{g} / E_{m}\right)+\xi} \\
\eta_{\tau}=\frac{\left(E_{g} / E_{m}\right)-1}{\left(E_{g} / E_{m}\right)+2} \\
\xi=\frac{2 \alpha_{g}}{3}=\frac{2 l_{g}}{3 t_{g}}
\end{gathered}
$$

where $\mathrm{E}_{\mathrm{c}}$ is the elastic modulus of the composite with randomly distributed graphite $\mathrm{E}_{\mathrm{g}}$ and $\mathrm{E}_{\mathrm{m}}$ represent the elastic modulus of $\mathrm{G}$ and $\mathrm{PVDF}$, and $\varphi_{f}$ is the volume fraction of $\mathrm{G}$ in the composites. $\alpha_{\mathrm{g}}, \mathrm{l}_{\mathrm{g}}$, and $\mathrm{t}_{\mathrm{g}}$ are the aspect ratio, length and thickness of the G. The Elastic modulus of the graphite is $1.50 \mathrm{E}+04 \mathrm{MPa}$, and that of pure PVDF is $722.15 \mathrm{MPa}$ from the experimental data. It can be found that the experimental data for $\mathrm{PVDF} / \mathrm{G}$ composites are in good agreement with the theoretical results under the hypothesis that $G$ randomly disperse throughout the polymer matrix. The enhanced mechanical properties are believed to arise from the variation of the aspect ratio $\alpha_{\mathrm{g}}$ values of graphite structure, particles or aggregates, in composites with different $G$ loading, as shown in Table (4).

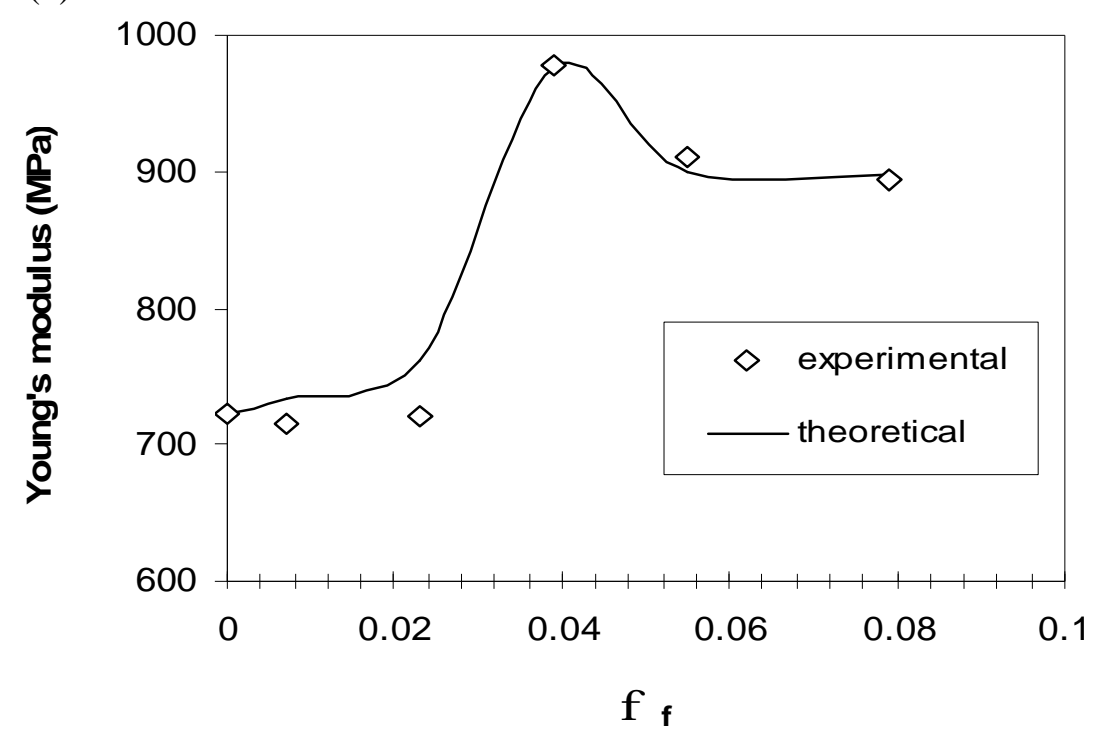

Fig. (4): Experimental Elastic modulus of the composites, calculated data derived from the Halpin-Tsai model under the hypothesis that $G$ randomly dispersed as 3D network throughout the polymer matrix. 
Table 4: The values of aspect ratio, $\alpha_{\mathrm{g}}$ with content of graphite

\begin{tabular}{|c|c|}
\hline Content of graphite & $\boldsymbol{\alpha}_{\mathrm{g}}$ \\
\hline 0.007 & 1.5 \\
\hline 0.023 & 1.5 \\
\hline 0.039 & 3000 \\
\hline 0.055 & 15 \\
\hline 0.079 & 4.5 \\
\hline
\end{tabular}

The variation of the aspect ratio with different graphite content can be summarized in the illustrative sketch shown in Fig. (5). The primary graphite particles have collapsed into ordered clusters. At low volume fractions $(0.7-2.3 \mathrm{vol} \%)$ of graphite, the clusters have a similar finite size and a spheroid shape (the aspect ratio, $\alpha_{\mathrm{g}}$ is about 1.5). At (3.9 vol\%), the clusters are dense and well ordered and form a highly interconnected network. So, the value of $\alpha_{g}$ increases sharply. At higher volume fractions (5.5-7.9vol \%), the thickness of clusters increases, which results in a decrease in the aspect ratio.

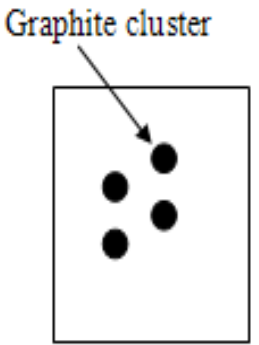

$0.7 \mathrm{vol} \%$

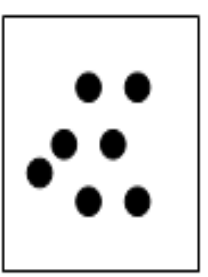

$2.3 \mathrm{vol} \%$

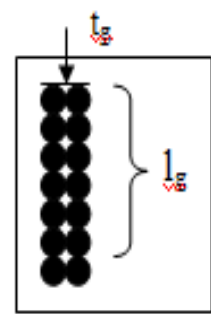

$3.9 \mathrm{vol} \%$

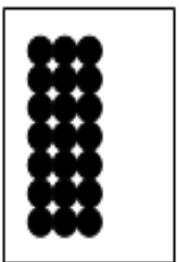

$5.5 \mathrm{vol} \%$

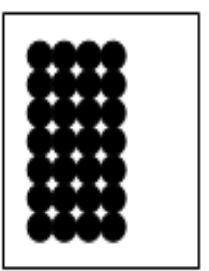

$7.9 \mathrm{vol} \%$

Fig. (5). Illustrative sketch for the microstructural changes in the investigated composites with different graphite content

\subsection{Mechanical behaviour as a function of temperature}

Figures (6-9) represents a set of stress-strain curves of the neat PVDF, $2.3 \mathrm{vol} \%, 5.5 \mathrm{vol} \%$ and $7.9 \mathrm{vol} \%$ of graphite at different working temperatures ranging from 30 to $90{ }^{\circ} \mathrm{C}$ and constant strain rate of $4.4 \mathrm{e}^{-3} \mathrm{sec}^{-1}$. Each curve consists of two distinct regions, the linear (or elastic) and the plastic regions. It is noticed that these regions are sensitive to both the working temperature and the concentration of graphite. The stiffness of the composites increases with increasing the graphite content up to $3.9 \mathrm{vol} \%$ and with decreasing the working 
temperature. In general, as the stress increases the resulting strain increases. This character may be attributed to the increase in the flexibility of polymer chain segments by the addition of an external force. This flexibility depends largely on both the working temperature and graphite content. Table.5 summarizes the variation of elastic modulus (E), tensile strength $\left(\sigma_{\mathbf{R}}\right)$, ultimate elongation $\left(\varepsilon_{\mathbf{R}}\right)$, and yield stress $\left(\sigma_{\mathrm{y}}\right)$ with graphite content at different temperatures. The results show that, E, $\sigma_{\mathbf{R}}$ and $\sigma_{\mathbf{y}}$ decrease, while $\varepsilon_{\mathbf{R}}$ increases with increasing the working temperature. This could be related to the flow process in polymer taking place with temperature [15]. The increase of working temperature affected the viscosity of the polymer, so slipping of chain segments takes place which decreases $\mathrm{E}, \sigma_{\mathbf{R}}$ and $\sigma_{\mathbf{y}}$ and in turn increases $\varepsilon_{\mathbf{R}}$. Also, the addition of graphite formed an obstacle for this motion [16].

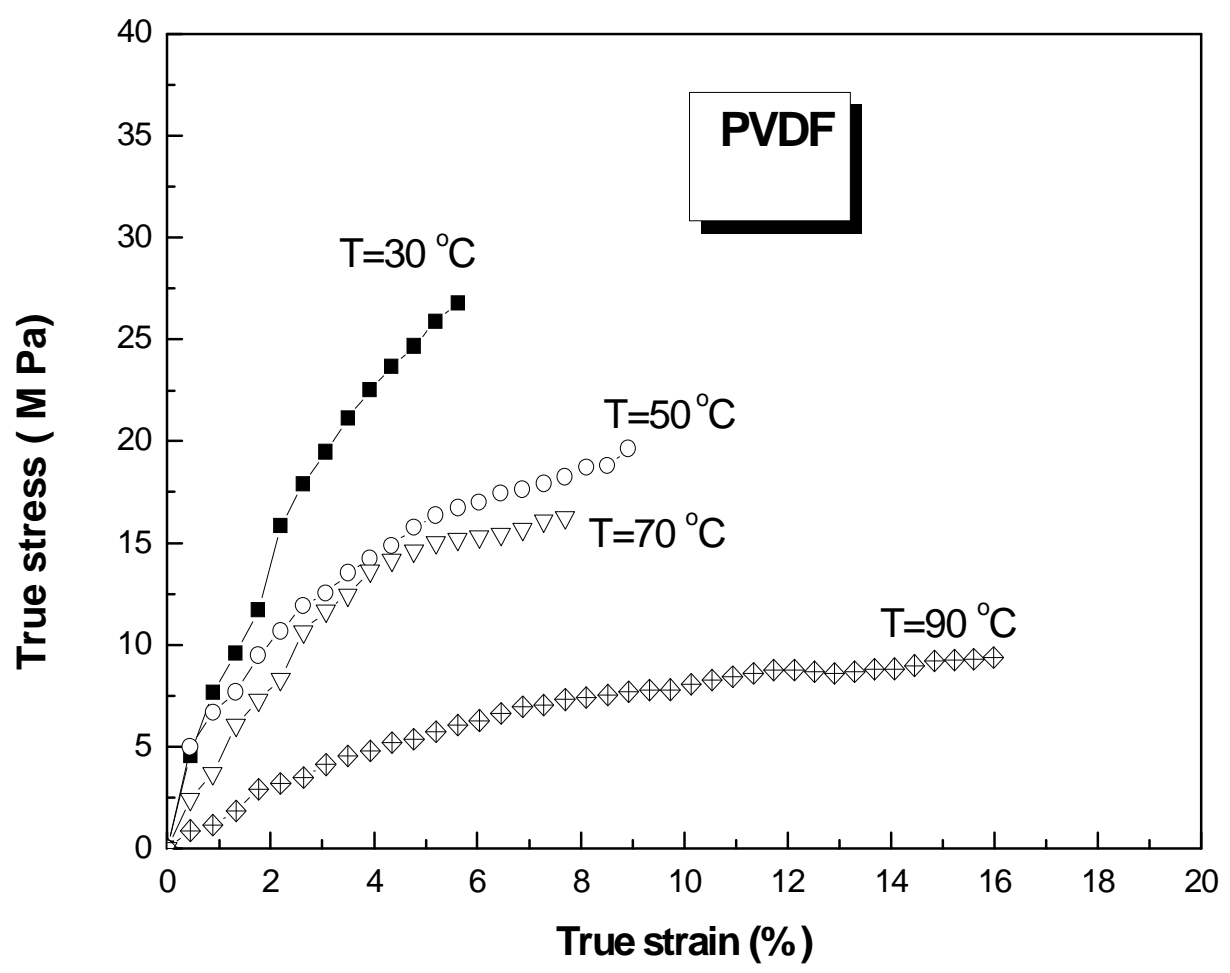

Fig. (6): Stress-strain curve for pure PVDF at different temperatures. 


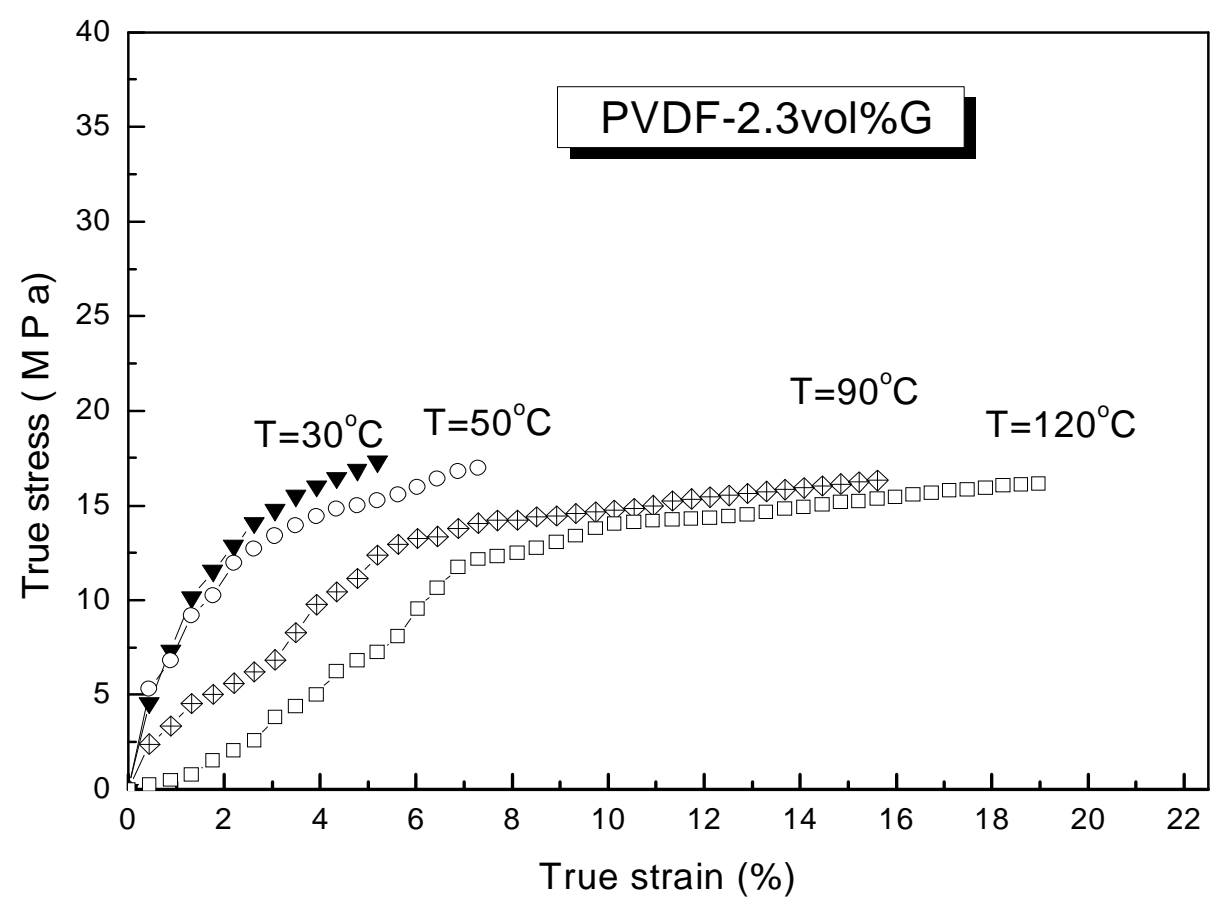

Fig. (7): Stress-strain curve of PVDF-2.3vol\%of graphite at different temperatures

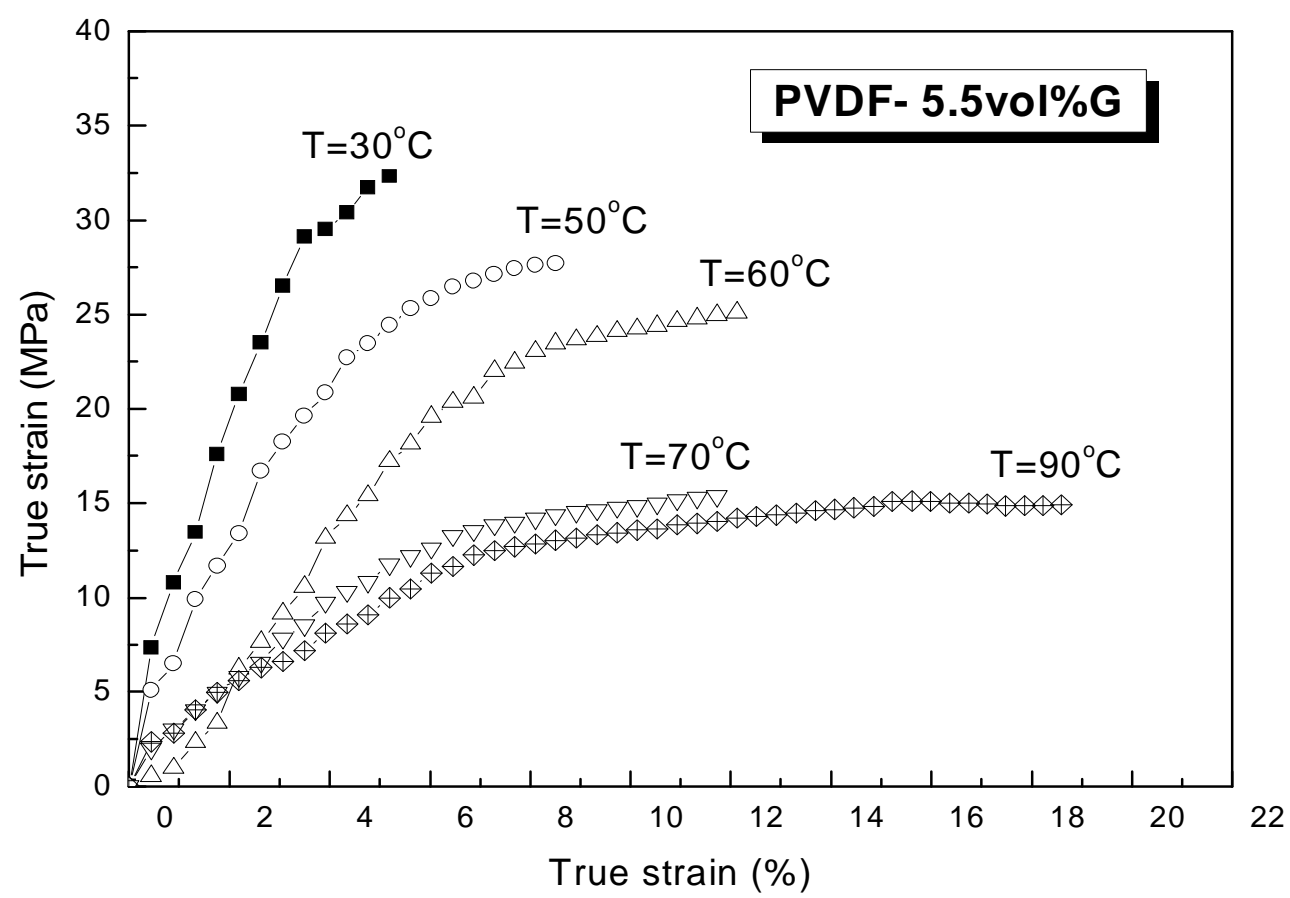

Fig. (8): Stress-strain curve of PVDF-5.5vol\% of graphite at different temperatures 
Table 5: Variation of Elastic modulus (E), tensile strength $\left(\sigma_{\mathbf{R}}\right)$, ultimate elongation $\left(\varepsilon_{\mathbf{R}}\right)$, yield stress $\left(\sigma_{\mathbf{y}}\right)$, and yield $\operatorname{strain}\left(\varepsilon_{\mathbf{y}}\right)$ with graphite content for the investigated composites.

\begin{tabular}{|c|c|c|c|c|c|}
\hline \multirow{2}{*}{$\begin{array}{c}\text { Content of } \\
\text { graphite } \\
(\text { vol\%) }\end{array}$} & \multirow{2}{*}{$\begin{array}{c}\text { Temperature } \\
\left({ }^{\circ} \mathrm{C}\right)\end{array}$} & \multicolumn{4}{|c|}{ Parameters } \\
\hline & & E (MPa) & $\sigma_{\mathbf{R}}(\mathbf{M P a})$ & $\varepsilon_{\mathrm{R}} \quad(\%)$ & $\sigma_{\mathbf{y}}(\mathbf{M P a})$ \\
\hline \multirow[t]{4}{*}{$\mathbf{0}$} & 30 & 722.15 & 26.77 & 5.61 & 7.66 \\
\hline & 50 & 491.40 & 19.62 & 8.92 & 4.99 \\
\hline & 70 & 413.67 & 16.23 & 7.69 & 2.44 \\
\hline & 90 & 154.00 & 9.37 & 15.98 & 1.81 \\
\hline \multirow[t]{3}{*}{0.7} & 30 & 715 & 12.44 & 4.7 & 3.37 \\
\hline & 60 & 345.54 & 13.08 & 7.6 & 5.71 \\
\hline & 70 & 249.69 & 5.32 & 4.3 & 3.30 \\
\hline \multirow[t]{4}{*}{2.3} & 30 & 720.55 & 17.32 & 5.19 & 4.58 \\
\hline & 50 & 506.94 & 16.99 & 7.2 & 4.48 \\
\hline & 90 & 377.88 & 16.32 & 15.2 & 5.03 \\
\hline & 120 & 100.39 & 16.13 & 18.9 & 1.53 \\
\hline \multirow[t]{4}{*}{3.9} & 30 & 978 & 33.59 & 6.45 & 11.01 \\
\hline & 50 & 488.22 & 11.63 & 4.3 & 3.44 \\
\hline & 60 & 346.84 & 13.48 & 6.4 & 3.068 \\
\hline & 70 & 321.94 & 9.34 & 5.1 & 4.06 \\
\hline \multirow[t]{5}{*}{5.5} & 30 & 910.7 & 32.32 & 5.19 & 7.35 \\
\hline & 50 & 640.69 & 27.67 & 8.51 & 4.295 \\
\hline & 60 & 292.95 & 25.09 & 12.12 & 3.90 \\
\hline & 70 & 272.98 & 15.36 & 11.72 & 3.03 \\
\hline & 90 & 197.66 & 14.89 & 18.6 & 2.81 \\
\hline \multirow[t]{5}{*}{7.9} & 30 & 894.2 & 23.84 & 3.92 & 8.66 \\
\hline & 50 & 526.62 & 22.75 & 6.86 & 3.76 \\
\hline & 60 & 317.99 & 25.17 & 10.53 & 3.57 \\
\hline & 70 & 215.75 & 13.62 & 8.92 & 1.89 \\
\hline & 90 & 204.49 & 12.67 & 15.60 & 3.74 \\
\hline
\end{tabular}




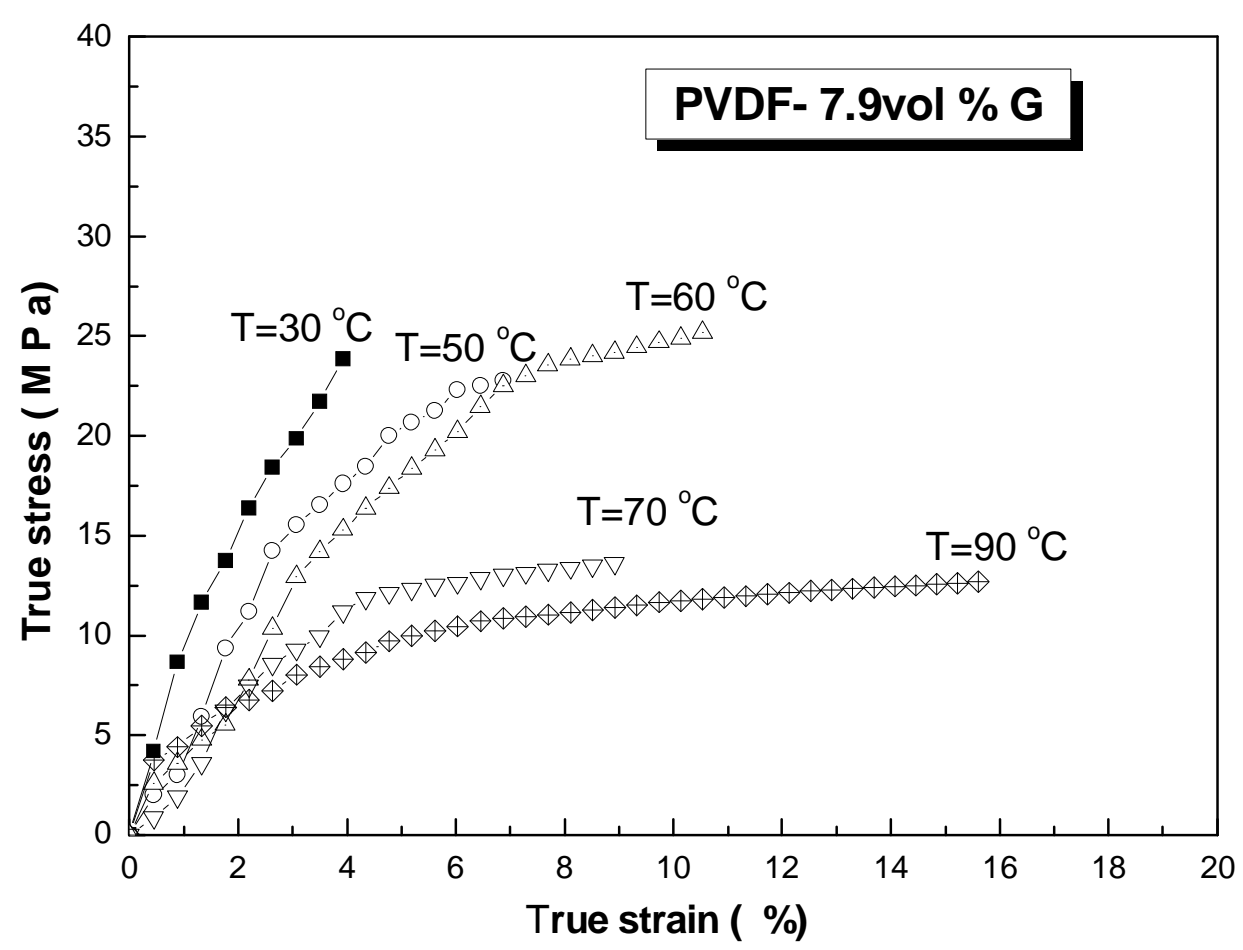

Fig. (9): Stress-strain curve of PVDF-7.9vol\%of graphite at different temperatures

\section{Conclusion}

The incorporation of graphite particles in PVDF improved the mechanical properties of composites up to $3.9 \mathrm{vol} \%$, after that the mechanical properties deteriorates. SEM and DSC analyses were used for understanding the morphology, crystallinity and crystal form of PVDF/graphite composites. Morphology of the fracture surfaces showed that tensile properties are affected by graphite contents. Composite containing 3.9vol\% of graphite exhibited the best compacted structure. DSC measurement indicated that graphite content has significant influence on the degree of crystallinity, $\chi_{c}$ for PVDF composites, where $\chi_{c}$ increases with increasing graphite content up to $3.9 \%$ of graphite. Above $3.9 \mathrm{vol} \%$, $\chi_{c}$ decreases with graphite loading. Besides, the melting behaviour suggested the presence of only $\alpha$-phase crystals in neat PVDF and its composites. The elastic modulus values obtained from the stress - strain curves are in close agreement with those calculated by Halpin-Tsai's model, taking into account the variation of the aspect ratio of the graphite structure. The mechanical parameters $\mathrm{E}, \sigma_{\mathrm{R}}$ and $\sigma_{\mathrm{y}}$, where found to decrease, while $\varepsilon_{\mathrm{R}}$ increases with increasing the working temperature. 


\section{References}

1. Deanna N. Busick, Richard J. Spontak, C. Maurice Balik: Effects of graphite content on the morphology and barrier properties of poly(vinylidene fluoride) composites. Polymer, 40, 6023 (1999).

2. Behzad Mohammadi, Ali Akbar Yousefi, Samad Moemen Bellah "Effect of tensile strain rate and elongation on crystalline structure and piezoelectric properties of PVDF thin films" Polymer Testing, 26, 42 (2007).

3. A. Salimi, A.A. Yousefi "FTIR studies of b-phase crystal formation in stretched PVDF films" Polymer Testing, 22, 699 (2003).

4. Fuan He, Jintu Fan, Sienting Lau." Thermal, mechanical, and dielectric properties of graphite reinforced poly(vinylidene fluoride) composites" Polymer Testing 27, 964 (2008).

5. C.R. Siviour, S.M. Walley, W.G. Proud and J.E. Field, "Mechanical behaviour of polymers at high rates of strain" J. Phys. IV France, 134, 949 (2006).

6. L. Laiarinandrasana, J. Besson, M. Lafarge, G. Hochstetter " Temperature dependent mechanical behaviour of PVDF: Experiments and numerical modelling" International Journal of Plasticity, 25, 1301 (2009.

7. Kumiko Asai, Masami Okamoto, Kohji Tashiro "Crystallization behavior of nano-composite based on poly(vinylidene fluoride) and organically modified layered titanate" Polymer, 49, 4298 (2008).

8. Chun-Hui Du, You-Yi Xu, Bao-Ku Zhu 'Plasticizer Effect of Dibutyl Phthalate on the Morphology and Mechanical Properties of Hard Elastic Poly(vinylidene fluoride) Fibers"' J.appl. polymer science, 114, 3645

9. W. Zheng and S. C. Wong :Electrical conductivity and dielectric properties of PMMA/expanded graphite composites., Composite Science and Technology, 63, 225 (2002).

10. Atheer Almasri, Zoubeida Ounaies, Yeon Seok Kim and Jaime Grunlan:Characterization of Solution-Processed Double-Walled Carbon Nanotube/Poly(vinylidene fluoride) Nanocomposites. Macromolecular Materials and Engineering 293, 123 (2008) .

11. Pramoda, K.; Mohamed, A.; Phang, I. Y.; Liu," Crystal transformation and thermomechanical properties of poly(vinylidene fluoride)/clay nanocomposites"' T. Polymer International, 54, 226 ( 2005).

12. H. Ismail, H. D. Rozman, R. M. Jaffri and Z. A. Mohd Ishak, "Oil Palm Wood Flour Reinforced Epoxidized Natural Rubber Composites: The effect of filler content and size," Euro. Poly. J., 33, 1627 (1997).

13. Z. A. M. Ishak and A. A. Bakar, "An Investigation on the potential of rice husk ash as fillers for Epoxidized Natural Rubber (ENR)," Euro. Poly. J., 31, 3, 259 (1995). 
14. Xin Wang, Hongyu Yang, Lei Song, Yuan Hu, Weiyi Xing, Hongdian Lu: Morphology, mechanical and thermal properties of graphene-reinforced poly(butylene succinate) nanocomposites. Composites Science and Technology Accepted (2011).

15. ROBERT S. HOY, MARK O. ROBBINS: Strain Hardening of Polymer Glasses: Effect of Entanglement Density, Temperature, and Rate. Journal of Polymer Science: Part B: Polymer Physics, 44, 3487 (2006).

16. Fuan He1, Jintu Fan1, Sienting Lau and Laiwa Helen Chan: Preparation, crystallization behavior, and dynamic mechanical property of nanocomposites based on poly(vinylidene fluoride) and exfoliated graphite nanoplate. Journal of Applied Polymer Science, 119, 1166 (2011). 